Original Research Paper

\title{
Design and Construction of Optical System to Detect of Ammonia Gas
}

\author{
Mohanad M. Azzawi, Mohammed Jabbar Hussein, Nibras K. Jebur and Halla F. Saad \\ Laser and Electro-Optic Centre, Directorate of Material Research, Ministry of Science and Technology, Iraq
}

\author{
Article history \\ Received: 05-12-2017 \\ Revised: 28-03-2019 \\ Accepted: 28-05-2019 \\ Corresponding Author: \\ Mohammed Jabbar Hussein \\ Laser and Electro-Optic Centre, \\ Directorate of Material \\ Research, Ministry of Science \\ and Technology, Iraq \\ Email: mohammed55865@yahoo.com
}

\begin{abstract}
The idea of research is the detection of gases using the transmitter and receiver system for electromagnetic radiation in the IR region using the optical absorption method. As a result of the interaction of the light with the gas molecules can be detect and measure gas pressure adoption absorption method. It was chosen best absorption band between (1.4-1.6) $\mathrm{um}$ at the wavelength 1.5 um to build a sensor for accurate measurement of ammonia gas which is characterized by precision, where he was the measuring pressure range (1-6) bar. The importance of the oil industry has been focusing on this kind of scientific research for the detection of ammonia gas.
\end{abstract}

Keywords: Ammonia Gas Sensing, Gas Analysis, Spectroscopy

\section{Introduction}

Ammonia $\left(\mathrm{NH}_{3}\right)$ is colorless gas composed of nitrogen and hydrogen with a sharp, penetrating dour. Sensitive and continuous monitoring of $\mathrm{NH}_{3}$ is relevant in several applications such as environment monitoring to quantify $\mathrm{NH}_{3}$ emissions from coal waste piles in combustion (Viveiros et al., 2014). DeNO processes, which are widely used in power plants and incinerators to reduce NOx emissions (Busca et al., 1998) or in medicine to analyses breath $\mathrm{NH}_{3}$ levels as a diagnostic tool (Narasimhan et al., 2001). The main optical gas sensor technologies are based on absorption spectroscopy of fundamental bands in the 3-25 $\mu \mathrm{m}$ spectral region, near infrared vibration overtone and combination bands from 1-3 $\mu \mathrm{m}$ (Viveiros et al., 2015). Various $\mathrm{NH}_{3}$ analysersand measuring methods have been developed, including the differential optical absorption spectrometer (Mount et al., 2002), tunable diode laser absorption spectrometer (Sickles et al., 1990), photoacoustic spectroscopy (Schmohl et al., 2002) and cavity ring-down spectroscopy (O'Keefe and Deacon, 1988). Fourier Transform infrared spectroscopy (Galle et al., 2000; Wyers et al., 1993). $\mathrm{NH}_{3}$ has a rich spectrum in the near infrared region, in the spectral range from $1450 \mathrm{~nm}$ to $1560 \mathrm{~nm}$. Recently, several works have been developed which use the absorption lines at $1532 \mathrm{~nm}$ and $1512 \mathrm{~nm}$ as the operating wavelength for $\mathrm{NH}_{3}$ sensing (Claps et al., 2001). The Wavelength Modulation Spectroscopy (WMS) technique has also been demonstrated in a system using a Distributed Feedback (DFB) laser diode with an emission wavelength at $1532 \mathrm{~nm}$ in conjunction with hollow optical waveguides (Fetzer et al., 2002).
Such waveguides were used as long-path sample cells (optical path length of $3 \mathrm{~m}$ ) which were coiled to reduce the physical extent of the system. A portable diode-laserbased sensor for $\mathrm{NH}_{3}$ detection, using vibration overtone absorption spectroscopy at $1532 \mathrm{~nm}$ (optical path length of $36 \mathrm{~m}$ ), was described using a fiber-coupled optical element that made a trace gas sensor rugged and easy to align (Huszár et al., 2008). The gas sensor was used primarily for $\mathrm{NH}_{3}$ concentration measurements. An $\mathrm{NH}_{3}$ sensor based on the combination of resonant photo acoustic spectroscopy and direct absorption spectroscopy techniques with a DFB laser diode operating at $1532 \mathrm{~nm}$, was also described (Besson et al., 2006).

\section{Detection Principles}

\section{Vibration Motion of $\mathrm{NH}_{3}$ Molecule}

Motion of molecule has three types. They are translation rotational and vibration motion. Translational motion is doing rectilinear movement as all of points do translation from space and this motion occurs vigorously in gas state. Rotational motion is that molecule rotates to rotating axis circumference that pass center of gravity and this motion offers factual information most about molecular structure. Oscillatory motion is regular motion that has amplitude that is fixed through bary center and it include periodic change of bond angle degree as well as bond length. Periodic change of bond length is called stretching vibration periodic change of bond angle degree is called flexural vibration. Vibration spectrum is used much in confirmation of molecule because it sights in infrared rays area mainly and shock depends on mass and 
bonding strength of oscillated composition atom, but is unrelated with composition atom. Figure 1 is a vibration mode of $\mathrm{NH}_{3}$ gas. 2 parallel mode that is $v_{4}, v_{1}$ and $v_{2}$ increased symmetrical, on the other hand, $v_{3}$ and $v_{4}, 2$ right angle modes, have degeneration style of asymmetry. These four vibration modes have four absorption bands in core infrared rays area $(0.78 \sim 2.5 \mathrm{um})$ by association each other as appear in Table 1 (Claps et al., 2001).

\section{Infrared Absorption}

If the molecule absorbs infrared rays, the molecule must occur essence change of dipole moment by vibration and rotational motion. When molecule oscillates, change amount of dipole moment is the more, infrared absorption is the stronger. In the case of uniformity nucleus species molecule such as $\mathrm{N}, \mathrm{H}, \mathrm{O}$
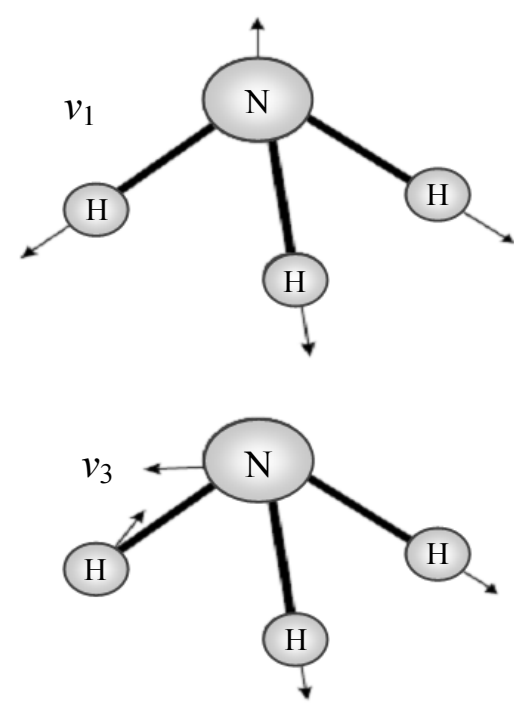

molecules do not absorb because essence change of dipole moment does not happen by vibration or rotational motion of molecule. $\mathrm{NH}_{3}$ 's dipole moment is 1.471D. So, we can know that infrared absorption occurs Fig. 2 shows that NH's absorption spectrum in 1.5, 2.0,2.3 um. Absorption spectrum in $1.5 \mathrm{um}$ and $2.3 \mathrm{um}$ is strong and effect of interference for other gas such as $\mathrm{H}_{2} \mathrm{O}$ or $\mathrm{CO}_{2}$ is less (Claps et al., 2001; Webber et al., 2001).

Table 1: Assignments for $\mathrm{NH}_{3}$ 's NIR spectra, listed roughly in order of contributionto the band (Claps et al., 2001)

\begin{tabular}{ll}
\hline NIR region & Band assignment \\
\hline $1.5 \mu \mathrm{m}$ & $v_{1}+v_{3}, 2 v_{3}, v_{3}+2 v_{4}, v_{1}+2 v_{4}, 2 v_{1}$ \\
$1.65 \mu \mathrm{m}$ & $v_{2}+v_{3}+v_{4}$ \\
$2.0 \mu \mathrm{m}$ & $v_{3}+v_{4}, v_{1}+v_{4}+2 v_{2}+v_{3}, 4 v_{2}+v_{4}, 2 v_{2}+2 v_{4}$ \\
$2.3 \mu \mathrm{m}$ & $v_{2}+v_{3}, v_{2}+2 v_{4}, v_{1}+v_{2}$ \\
\hline
\end{tabular}

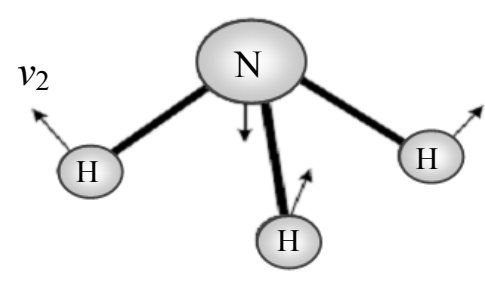

Fig. 1: $\mathrm{H}_{3}$ 's vibration modes (Claps et al., 2001)

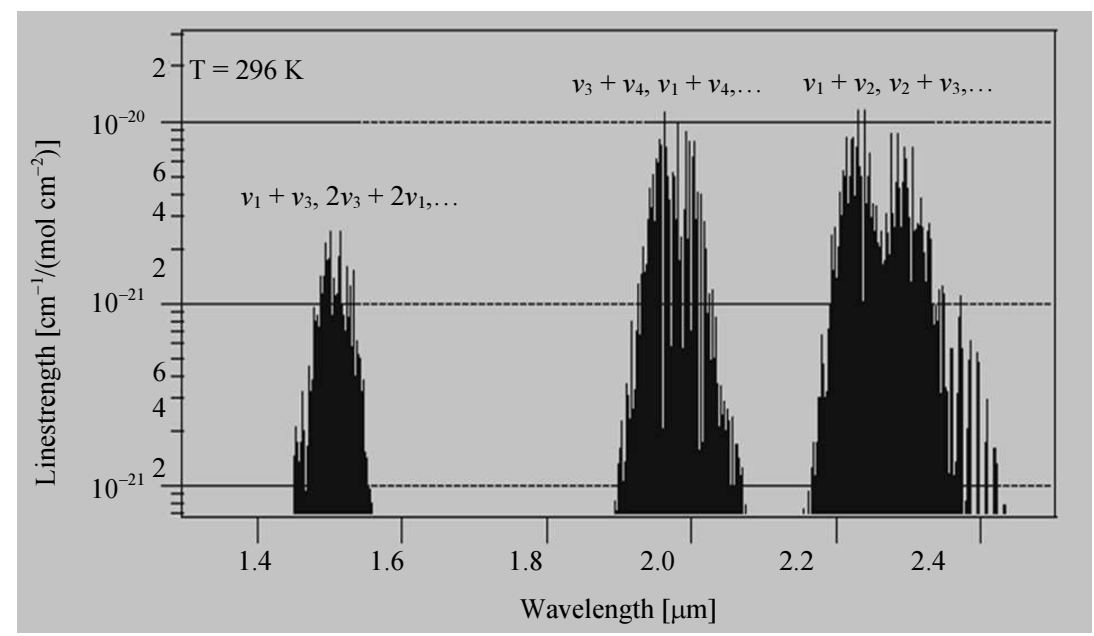

Fig. 2: $\mathrm{NH}_{3}$ 's absorption bands in the NIR (Chomsky, 2012) 


\section{Theory}

The fundamental theory that governing absorption spectroscopy for narrow-line width radiation sources is embodied in the Beer-Lambert law, Equation (1) and is described thoroughly in Ref. 3. The ratio of the transmitted intensity $I_{t}$ and initial (reference) intensity $\mathrm{I}_{0}$ of laser radiation through an absorbing medium at a particular frequency is exponentially related to the transition line strength $\mathrm{S}_{i}\left[\mathrm{~cm}^{-2} \mathrm{~atm}^{-1}\right]$, line-shape function $\phi[\mathrm{cm}]$, total pressure $P$ [atm] of the medium, mole fraction of the absorbing species $x_{j}$ and the path length $L[\mathrm{~cm}]$ through which the radiation passes (Claps et al., 2001; Webber et al., 2001):

$$
\frac{I_{t}}{I_{r}}=\exp \left(-S_{i} \varnothing P x_{j} L\right)
$$

The two laser intensities can be converted to absorbance $\propto(v)$ and related to the transition parameter by:

$$
\propto(v)=\ln \left(\frac{I_{t}}{I_{o}}\right)=S_{i} \varnothing P x_{j} L
$$

Absorption coefficient, $\varepsilon(v)$ is defined with (3):

$$
\varepsilon(v)=S_{i} \varnothing(v) P
$$

Absorption, $\propto(v)$ can appear in simple form with way(4) from way(2):

$$
\propto(v)=\varepsilon(v) x_{j} L
$$

Here, absorbance $\propto(v)$ is proportional in concentration $\left(x_{j}\right)$ of measurement gas.

\section{Experimental Setups}

The basic elements of an experiment for measuring absorption spectra of the $\mathrm{NH}_{3}$ gas by sensor system is shown in Fig. 3 and 4 . The main block of the system consists an Electrical lamp source whose radiation is directed pass through an absorbing gas medium of known path length and monitored with a detector. The Electrical lamp source with optical filter at $1.5 \mathrm{um}$ is wavelength-tuned across the absorption transition and the transmitted intensity is recorded with the detector (THORLAB PDA30G - EC type PbS Amplified Detector 1.0-2.9 um) or analyzed spectrometer (Zolix - monochromatic - omni - 500) to determine the integrated area of the absorption line shape. Two modes can be chosen IR transmitter lamp at wavelength $1.5 \mathrm{um}$ connected with driver modulated circuit by the square mode of (1-3) $\mathrm{Hz}$ frequency and $\mathrm{CW}$ mode. Optoelectronic receiver includes Indium Gallium Arsenide (InGaAs) photodiode with a low noise amplifier circuit for monitor signal detection were chosen because of their good stability and responsively for 1.5 um radiation. The sensor was comprised of a single pass cell with $34 \mathrm{~cm}$ optical path length. The pressure monitored by gauges at the entrance and exit of $\mathrm{NH}_{3}$ gas at pressure (1-6) bar. The cell was heated to a temperature of $30^{\circ} \mathrm{C}$ to minimize ammonia adsorption on its glass walls and to prevent potential water condensation on the cell mirrors, as monitored with thermocouple at cell.

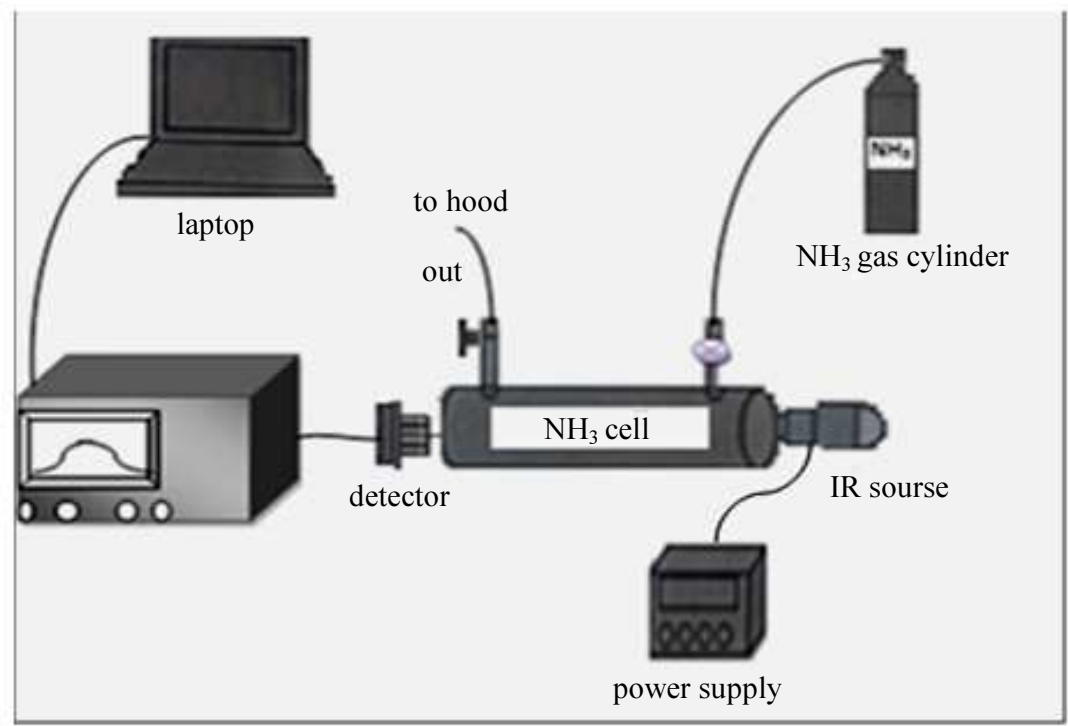

Fig. 3: Ingle Path $\mathrm{NH}_{3}$ gas sensor with Zolix - monochromator (omni - 500) 


\section{Results and Discussion}

It has been monitoring the absorption band through spectral scanning ammonia gas in the infrared region between (700-1700 um), this is illustrated in Fig. 4. It has been focusing only on the strong absorption band between (1400-1600 um) in ammonia gas detection.

It was built optical sensor for measuring the ammonia gas pressure without spectral analyzer and with minimal optical noise; Using optical filter type (THORLABS FB1500 -12 -1500 nm FWHM =12 nm) is compact with photodiode $(\mathrm{PbS})$ is coupled to gas sensor cell and the second end of the gas sensor cell provider optical light source works continuous and pulse mode. In the case of a small amount of water vapor inside the ammonia gas cell. The optical filter was used to separate the overlap spectrum between the ammonia gas and water vapor. The first part: to examine the optical system for measuring the ammonia gas sensor at different pressures in (1-6) bar under temperatures constant $\left(\mathrm{T}=30^{\circ} \mathrm{C}\right)$, with optical spectrum analyzer and filter at $1.5 \mathrm{um}$. Figure 5 shows the light intensity levels as a function of gas pressure was record. Then intensity peak of the spectra is at around $1500 \mathrm{~nm}$ and the intensity of light passing through the gas decreases with increased gas pressure, due to increased absorption.
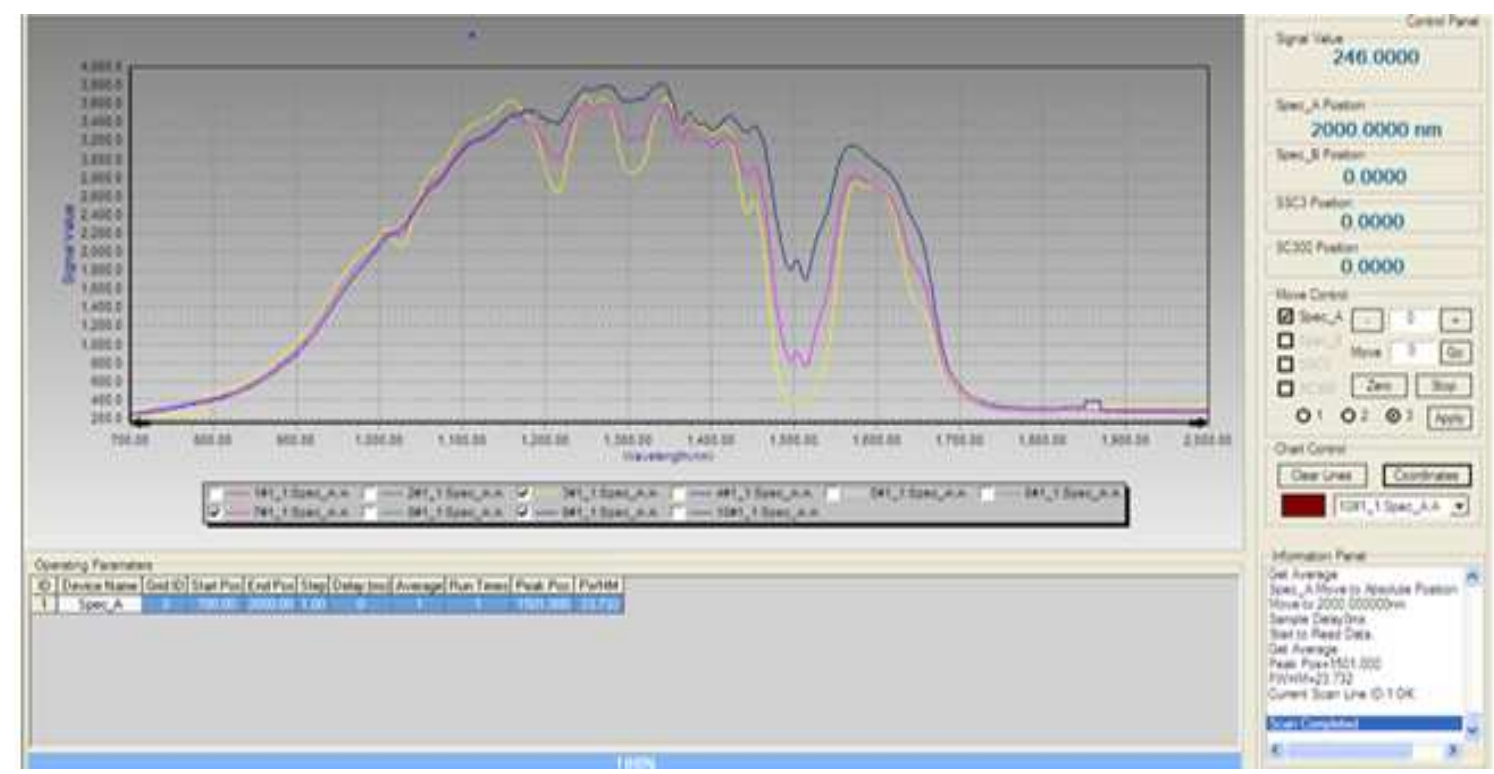

Fig. 4: Represents three absorption band of ammonia gas regions

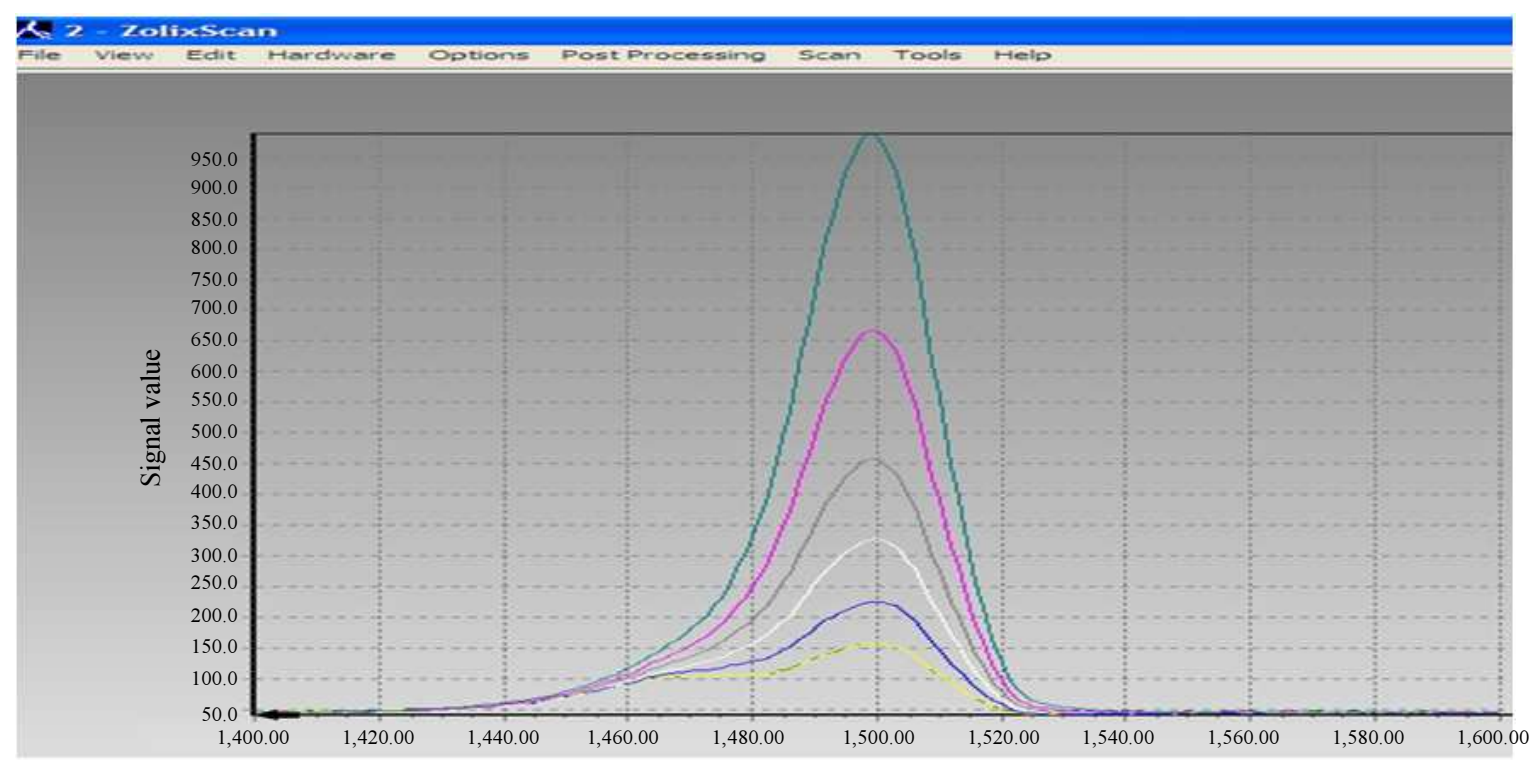

Fig. 5: Test $\mathrm{NH}_{3}$ gas sensor used optical spectrum analyzer with a filter at $1.5 \mathrm{um}$ 


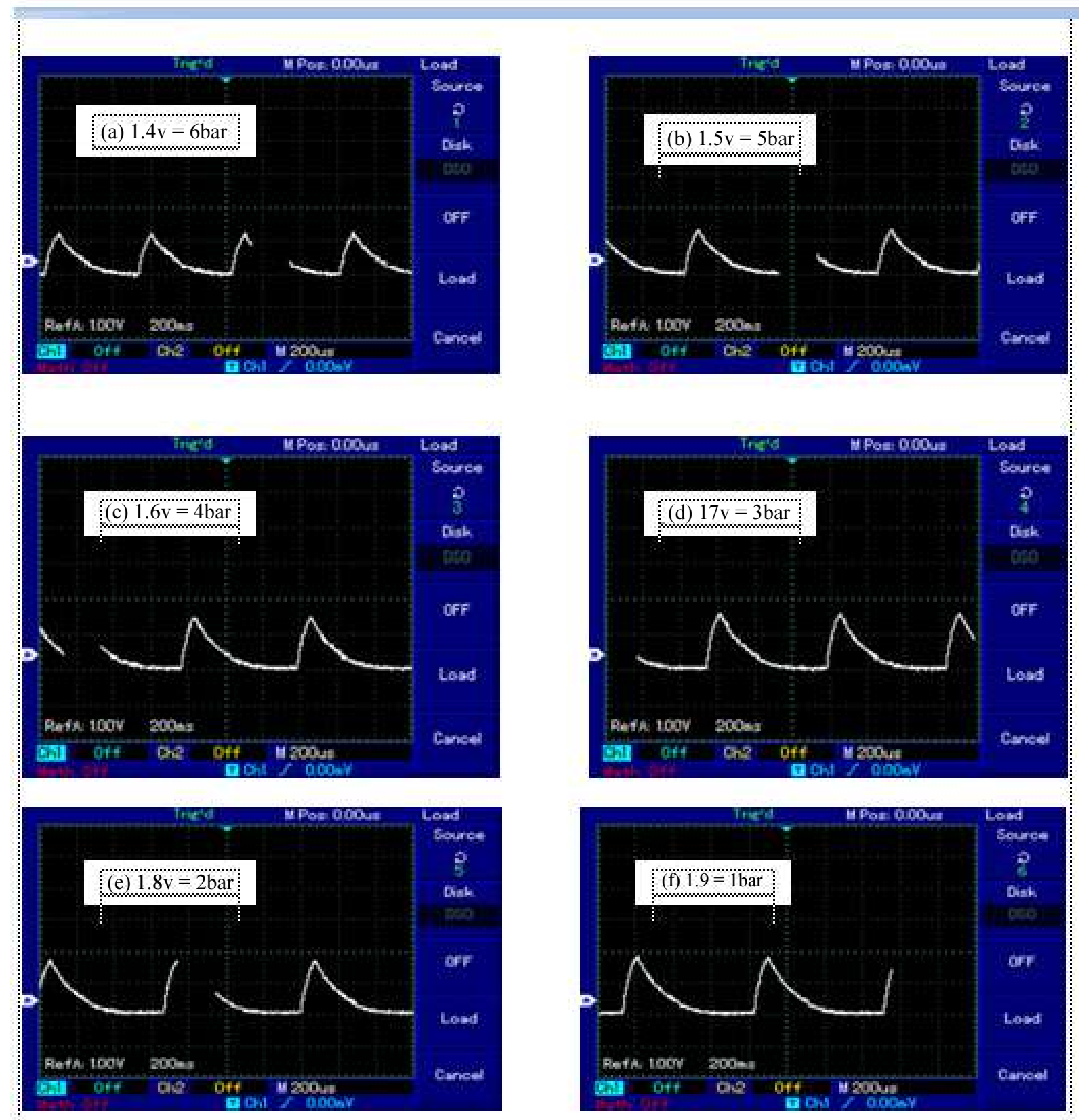

Fig. 6a-f: Represents the output signal voltage for six cases at $\mathrm{T}=29.5^{\circ} \mathrm{C}$

The proposed sensing system shows line responses in the gas ammonia range from 1 to 6 bar.

Second part: Detector has been replaced with optical filter instead of the spectral analyzer. And make the same previous tests for pressure and temperature as shown in Fig. 3. It was measured and recorded output voltages values as a function of ammonia gas pressure as shown in Fig. 6a-6f. These results were compared with pressure gauge used to obtain accurate results for measuring the ammonia gas pressure. This system could be developed for measuring the highest pressure gas.

\section{Conclusion}

In this study, we have been designing and building a system for measuring the ammonia gas pressure in the infrared region. The work includes two parts: The first measurements uses spectral analyzer to see stronger absorption regions between (700-1700 um) and the focus was exclusively on the 1.5 um region.

The second parts, the sensing system of gases using the transmitter and receiver system in the IR region $(1.5 \mathrm{um})$. Work the system for measuring the 
ammonia gas limits (1-6) bar. The advantages of this sensor system is high accuracy and easy in laboratory and industrial applications.

\section{Acknowledgment}

The authors would like to thank Electro-Optic Centre, Directorate of Material Research, Ministry of Science and Technology, Iraq for providing the research facilities.

\section{Author's Contributions}

Mohanad M. Azzawi and Mohammed Jabbar Hussein: Work experimental and write manuscript.

Nibras K. Jebur and Halla F. Saad: Check crammer.

\section{Ethics}

Authors should address any ethical issues that may arise after the publication of this manuscript.

\section{References}

Besson, J.P., S. Schilt, E. Rochat and L. Thévenaz, 2006. Ammonia trace measurements at ppb level based on near-IR photoacoustic spectroscopy. Applied Phys. B, 85: 323-328. DOI: 10.1007/s00340-006-2335-6

Busca, G., L. Lietti, G. Ramis and F. Berti, 1998. Chemical and mechanistic aspects of the selective catalytic reduction of $\mathrm{NO}_{\mathrm{x}}$ by ammonia over oxide catalysts: A review. Applied Catalysis B: Environ., 18: 1-36. DOI: $10.1016 / \mathrm{S} 0926-3373(98) 00040-\mathrm{X}$

Chomsky, N., 2012. What is Special about Language? SBS Lecture Series: Noam Chomsky, University of Arizona.

Claps, R., F.V. Englich, D.P. Leleux, D. Richter and F.K. Tittel et al., 2001 Ammonia detection by use of near-infrared diode-laser-based overtone spectroscopy. Applied Opt., 40: 4387-4394. DOI: 10.1364/AO.40.004387

Fetzer, G.J., A.S. Pittner, W.L. Ryder and D.A. Brown, 2002. Tunable diode laser absorption spectroscopy in coiled hollow optical waveguides. Applied Opt., 41: 3613-3621. DOI: 10.1364/AO.41.003613

Galle, B., L. Klemedtsson, B. Bergqvist, M. Ferm and K. Törnqvist et al., 2000. Measurements of ammonia emissions from spreading of manure using gradient FTIR techniques. Atmos. Environ., 34: 4907-4915. DOI: $10.1016 / \mathrm{S} 1352-2310(00) 00220-\mathrm{X}$
Huszár, H., A. Pogány, Z. Bozóki, Á. Mohácsi and L. Horváth et al., 2008. Ammonia monitoring at ppb level using photoacoustic spectroscopy for environmental application. Sensors Actuators B: Chem., 134: 1027-1033. DOI: $10.1016 /$ j.snb.2008.05.013

Mount, G.H., B. Rumburg, J. Havig, B. Lamb and H. Westberg et al., 2002. Measurement of atmospheric ammonia at a dairy using differential optical absorption spectroscopy in the mid-ultraviolet. Atmos. Environ., 36: 1799-1810. DOI: 10.1016/S1352-2310(02)00158-9

Narasimhan, L., W. Goodman and C.K.N. Patel, 2001. Correlation of breath ammonia with blood urea nitrogen and creatinine during hemodialysis. Proc. Nat. Acad. Sci., 98: 4617-4621. DOI: $10.1073 /$ pnas.071057598

O'Keefe, A. and D.A. Deacon, 1988. Cavity ring-down optical spectrometer for absorption measurements using pulsed laser sources. Rev. Scientific Instruments, 59: 2544-2551. DOI: 10.1063/1.1139895

Schmohl, A., A. Miklós and P. Hess, 2002. Detection of ammonia by photoacoustic spectroscopy with semiconductor lasers. Applied Opt., 41: 1815-1823. DOI: 10.1364/AO.41.001815

Sickles, J.E., L.L. Hodson, W.A. McClenny, R.J. Paur and T.G. Ellestad et al., 1990. Field comparison of methods for the measurement of gaseous and particulate contributors to acidic dry deposition. Atmos. Environ., 24: 155-165. DOI: 10.1016/0960-1686(90)90451-R

Viveiros, D., J. Ferreira, S.O. Silva, J. Ribeiro and D. Flores et al., 2015. Ammonia sensing system based on wavelength modulation spectroscopy. Photonic Sensors, 5: 109-115. DOI: $10.1007 / \mathrm{s} 13320-015-0242-3$

Viveiros, D., J. Ribeiro, J.P. Carvalho and J. Ferreira, 2014. Fiber optic sensing system for monitoring of coal waste piles in combustion. Proceedings of the 23rd International Conference on Optical Fiber Sensors, (OFS' 14), At Santander, Spain, pp: 1-4 DOI: $10.1117 / 12.2059640$

Webber, M.E., R. Claps, F.V. Englich, F.K. Tittel and J.B. Jeffries et al., 2001. Measurements of $\mathrm{NH}_{3}$ and $\mathrm{CO}_{2}$ with distributed-feedback diode lasers near $2.0 \mu \mathrm{m}$ in bioreactor vent gases. Applied Opt., 40: 4395-4403. DOI: 10.1364/AO.40.004395

Wyers, G., R. Otjes and J. Slanina, 1993. A continuousflow denuder for the measurement of ambient concentrations and surface-exchange fluxes of ammonia. Atmos. Environ., 27: 2085-2090. DOI: 10.1016/0960-1686(93)90280-C 